\title{
A respeito de trágicos e ébrios
}

\author{
Carmem GADELHA ${ }^{1}$ \\ Universidade Federal do Rio de Janeiro - UFRJ
}

Pensar a vigência e o vigor da tragicidade no teatro contemporâneo exige esforços de retomada de alguns dos traços que, ao longo das épocas, deram sustentação lógica e materialidade aos conceitos. Corpo/espaço/tempo encontram-se entre esses traços, instituindo entre si fronteiras e interpenetrações, mútuas dependências.

O presente trabalho refaz trajetórias antes percorridas em congressos da ABRACE ${ }^{2}$ e do HCTE/UFRJ ${ }^{3}$; e tenta apontar desdobramentos futuros de uma pesquisa que se atém a processos. Neles, as configurações teatrais históricas se deixam flagrar, de modo a traçarem-se entre elas contrastes, contiguidades, analogias. A representação teatral se exibe e fulgura, faz-se e desfaz-se, num incessante ir-e-vir entre dobras e redobras.

Recorrente, na discussão da tragédia, é sua possibilidade de efetuar-se entre cristãos. O Livre-Arbítrio informa onde está o erro, responsabilizando inteiramente o humano. Isto afasta a tragédia; nela, é precisamente o engano que faz cair em desmedida (o que é próprio dos homens, o que pertence aos deuses?). Aceitemos: só entre os gregos houve tragédia; impõe-se, deste modo, a identificação de elementos de tragicidade em outras condições históricas e culturais.

Ficam os conflitos da subjetividade, tanto no terreno coletivo (a cidade, a política) quanto individual (transes da consciência, da relação de si para consigo e os outros). Por um lado, somos remetidos à tensão com a ideia de espetáculo (algo que se dá a ver), após a festa artaudiana; por outro, há que enfrentar riscos teóricos de tomar a sociedade atual como lugar receptivo ao retorno do trágico.

Aqui, privilegiam-se alguns momentos, tomando-se por base a luta posta entre o ritual e o teatro, as fendas e os abismos da cena. Em primeiro lugar, os gregos - a tradição e a democracia; em seguida, a subjetividade moderna apanhada em Tchekov e na cena de Appia, passando antes rapidamente por pós-renascentistas e romântico-iluministas. Finalmente, nossa lida contemporânea com forças de retorno da força trágica, na crise das

\footnotetext{
${ }^{1}$ Mestra e Doutora em Comunicação e Cultura pela Escola de Comunicação da UFRJ. Professora de "Poética do Espetáculo" e "Teoria do Drama" do Curso de Direção Teatral da mesma Escola. E-mail: carmem@gadelha.com.br/ cafezeiro@uol.com.br.

2 VI e VII Congressos da Associação Brasileira de Pesquisa e Pós-Graduação em Artes Cênicas (São Paulo, 2010; Porto Alegre, 2012); VI Reunião Científica da mesma instituição (Porto Alegre, 2011).

${ }^{3}$ V Congresso de História das Ciências e das Técnicas e Epistemologia: Scientiarum Historia V: Filosofia, Ciências e Artes: Conexões Interdisciplinares (Rio de Janeiro, 2012).
} 
narrativas e fabulações. O propósito é confrontar modernos e contemporâneos entre si e com os fundamentos arcaicos e clássicos.

Em Hesíodo (1981), através do canto das Musas, Mnemósine rompe e reestabelece limites temporais. Os suportes são o corpo e a voz do poeta. Este cultor de Memória zela pela justiça, fazendo-a vigorar onde a lei não é escrita. Nomear deuses e homens é torná-los presentes no tempo e no espaço, conferindo-lhes ser e verdade. Porém, a aparição é também ocultação, pois as Musas podem mentir e omitir, negando o ser. Este discurso é abrigado por temporalidades simultâneas e contíguas - eternidades manifestas na aparição do ser. As origens constituem o sempre e o agora, sem anterioridades e posterioridades. Tudo é Múltiplo; “tudo é um” (Heráclito, 1980, p. 81) porque uns participam da natureza de outros - recíprocas imanências, permanências, contemporaneidades. Sendo filhas de Zeus, as Musas são também a origem do pai (suas mães), porque o retiram do não-ser ao pronunciar o seu nome. Ficará para Platão (1963) dizer, cerca de dois séculos depois, que o nome é signo da coisa: a linguagem tornou-se racional, hipotática e abstrata. A realidade humana, no limiar Memória/História, eclode em máxima tensão com o Mito, sob regime democrático e palavra escrita. Daí a fundação do teatro: a aparição tornou-se referência e corporificação de tempos e coisas ausentes, dados ao olhar como re-presentação. $\mathrm{O}$ discurso encantatório de Hesíodo (ou dos ditirambos) cede a um tempo abstrato e préexistente a tudo, homogêneo e inalterável pelos acontecimentos: tempo histórico e quantificável. A ação teatral será descrita pela metafísica aristotélica, numa reta de passado, presente e futuro - cronologia correspondente à lógica de causa e efeito. No âmago do arcaico e preparando a chegada da polis, o aparecimento do discurso lírico falara da experiência individual (sem que se tratasse ainda, claro, da dicotomia sujeito/objeto); encaminhava-se o agente teatral, em vínculo indissolúvel com a ação (embate com a cidade e os deuses).

Os antigos rituais reconfirmavam crenças, em intimidade com os saberes. Ato político-religioso, a fala do poeta (re)velava verdades e fundamentos da vida social: regras, anseios, indagações. Homero e Hesíodo modelavam sentidos para guerra e paz, plantio e colheita. Na democracia, refazem-se arranjos saberes/poderes. O sábio - poeta detentor de magias - dá lugar ao filósofo. A gestão da cidade submete-se ao juízo dos cidadãos, que investem em se persuadirem uns aos outros, no tribunal e na ágora. A religião choca-se com a realidade política e o pensamento racional. No ditirambo, alguém se separou do coro para falar em nome próprio. A perda de consenso impõe o diálogo - logos partido (diâ). Nos 
conflitos herói/cidade, herói/mito, cidade/tradições, a tragédia manifesta as incertezas em palavras e ações mergulhadas em desmedida.

A democracia grega requer a normatização dos comportamentos em função da "governamentalidade" (FOUCAULT, 2010). A veridicção implica formações de saberes, tecnologias de poder e práticas de si - produção subjetiva compreendida como cidadania. Dizer a verdade é direito e obrigação: parresia. A fala franca é passível de aprendizado, no cuidado consigo e a cidade. A parresia tece-se em todas as direções, variando no tempo; não se integra a doutrinas; voltada para o indivíduo e sua virtude (arethê) de coragem, vigora no campo político. Creonte diz a Édipo que busque a verdade. Serão ambos obrigados a ouvila, (des)entendê-la e proferi-la, (des)entendendo-a - fugindo à ambiguidade do oráculo ou enfrentando-a. O dizer-a-verdade não se detém na retórica (arte das estratégias de demonstração, persuasão, ensino, discussão). A parresia é desafio, insulto, crítica: ato de coragem. Pedagogia abrupta, pode conduzir ao furor e à injustiça - bybris trágica. De natureza agonística, a parresia não se reduz, no entanto, à controvérsia; trata-se, antes, da luta revelação/ocultação - alétheia. Este dizer-a-verdade não pertence à erística ou à pedagogia, à retórica, à persuasão ou à demonstração; não está nos efeitos do discurso, em suas estruturas internas ou finalidades. A verdade é parresia quando dizê-la desencadeia perigo: efeito no interlocutor, ricochete sobre o locutor - afetação e risco de morte; o caos primordial espreita a cidade, a verdade o fustiga. No discurso trágico, a teia aracnídea enreda os cidadãos e o herói-parresiasta. Édipo foge às predições e cai nas malhas dos deuses; depois, tendo furado os próprios olhos, não sabe até onde a decisão coube à divindade. Uma nova razão traz dificuldades nas designações: é possível falar em tragédia fora e depois da Grécia? A que se referem trágico e tragicidade?

A vida pública tensiona-se com os atos do herói. Certa analogia se estabeleceu entre Racine e os gregos, a partir da responsabilidade do homem com a sociedade. Em clássicos e barrocos, o embate do sujeito moderno consigo mesmo: reflexividade em tensão com o agir (Hamlet, Segismundo, Fedra).

Com os românticos, o desejo de morte para o reencontro com a liberdade do espírito desfaz o conflito com a transcendência. A democracia moderna proclama o direito à dissidência, o que resulta em drama burguês. $O$ trágico refugia-se no conflito de consciência. $\mathrm{O}$ sentido do mundo mergulha nas sombras infinitamente percorridas do Fausto de Goethe. Após a busca romântico-iluminista pelo trágico nos clássicos franceses ou em Shakespeare, não importa oposição ou síntese. Importam a sala-de-estar e os "males do século”. Esperanças numa pedagogia realista e reformadora mesclam-se com evidências 
de malogro. À falta de ação, o trágico invade sonhos e ostenta (ir)realidades nos desvãos do sujeito. Tristeza algo cômica se insinua no lirismo, numa poesia sem eloquência. Abre-se fenda definitiva entre a cena e a literatura.

Wagner considerou harmônica a união das diferentes expressões - últimos suspiros do aristotelismo: buscavam-se no passado os fundamentos de uma sociedade livre. Em Bayreuth, a visibilidade igualmente distribuída garantiria a democracia do olhar; supunha-se reincorporar a alma das tradições. O trágico identificou-se ao melodrama (que confiava em soluções de moralização), diria Nietzsche (1982): o problema está no viver as vicissitudes do corpo e não nas "consolações metafísicas".

O palco burguês não alcança a extensão da vida social, malgrado Brecht. $\mathrm{Na}$ era da luz elétrica, dos transportes acelerados e da comunicação; ao lado do brilho da cultura de massas, as sombras do psiquismo confinam a tragicidade. $\mathrm{O}$ senso comum vê tragédia em qualquer manifestação de sofrimentos. A utopia marxista só se admite como trágica pela incerteza da revolução, com suas intensidades de emoção coletiva. Mesmo assim, há o comprometimento com a razão científica.

Nosso problema agora é apanhar, na subjetividade moderna, a oposição história da sociedade/história pessoal. O corpo, descoberto como lugar de registro de hábitos motores capazes de repetir o passado, prolonga percepções antigas e liga-as ao atual (BERGSON, 1990). Esta sede das paixões é instrumento de ação, através de respostas a estímulos e escolhas de movimentos. A memória evoca percepções múltiplas, condensando durações: espessuras de tempos, intensidades e espaços. Isso libera a narrativa do encadeamento aristotélico e da dicotomia matéria/espírito. O corpo é imagem feita de imagens - de outros corpos e dos lugares por eles ocupados; perceber é eliminar imagens para circunscrever o corpo e seus "outros". As imagens ultrapassam a percepção, tornando-a "menor" do que elas: resistência das coisas à representação.

As personagens de Tchekov ambicionam completar o que falta à percepção do presente por meio da restauração do passado; deste modo, sonham produzir o real abarcá-lo, precedê-lo e moldá-lo ao que supõem sua experiência. O sistema sensório-motor é movimentado pelas lembranças: não-ação, porque o agente é apassivado (apaixonado) pelo passado - tempo de extensões homogêneas e contínuas, livre da rugosidade do presente. Agir seria recortar extensões, mobilizar virtualidades e reações; mas Liúba deseja livrar-se das afecções, refugiando-se na memória (não mais mítica, mas inscrita na interseção corpo/espírito). O que se exibe é um lusco-fusco: transparência e opacidade do sujeito. 
Se o corpo é um ponto no espaço e a percepção um ponto no tempo, os afetos conferem extensão ao corpo e duração à percepção. No agir do corpo sobre si e os outros, os vazios se preenchem em percursos de tempo e espaço. Instalada no passado, Liúba é anacrônica; não tem futuro, como sujeito individual ou classe. No presente, sua figura é espectro acossado pela venda iminente do cerejal e os avanços da futura revolução proletária. A memória faz-se de afecções do corpo e perceptos de imagens de fora; interioridade e exterioridade diferem em grau e não em natureza, porque as ações reais e virtuais se interpõem entre elas, transcendendo a matéria, mas aproximando dela o espírito convertido em imanência - ressonâncias entre os corpos.

A vida transfigurada em memória estende planos de diferentes intensidades de consciência, num perpétuo deslocamento da ação ao devaneio, em Tchekov. O passado não ressoa no presente, nenhuma lembrança impulsiona decisões. O temor de Liúba à indeterminação (com ela, o futuro) desfaz os liames com o trágico - agir em direção à liberdade e à aceitação do devir. A mesma modernidade, que despoja o texto teatral de autoridade metafísica, dispõe a cena sobre a relação corpo/espaço, mediada pelo movimento - espaço/tempo (APPIA, s.d.). Desta tensa duração (heterogeneidades e desarmonias) resultam narrativa e encenação. Ao ator cabe sintetizar tempo/espaço na sucessão de instantes: escultura móvel e pintura mutante. Neste corpo se processam vicissitudes de sentido: entendimento assaltado pela explosão das significações. Nos desvãos do sujeito em conflito consigo mesmo, na busca dos elos entre as coisas e os signos - eis a tragicidade moderna, se houver. Em Appia e Tchekov (tomados aqui como paradigmas, entre muitos possíveis), o corpo emerge como topos de relações. Incompletude da marionete que antes era ligada à alma, na obsessão romântico-iluminista (KLEIST, s.d.; SCHILLER, 1997; DIDEROT, 1973) e entre os encenadores modernos é produtora de figurações às quais se ata por fios invisíveis.

Artaud compreendeu o preço de saber-se furtado de si: a palavra é sempre de outro, o corpo é penetrado pelo outro (DERRIDA, 1995). Escavando a crueldade, Artaud (1984) expõe a representação: o que temos não é um corpo, mas um duplo sempre afastado de si, aquém e além do aqui-agora. Este desejo de presente e presença, jamais satisfeito porque a representação eternamente retorna, desfaz os contornos da cena e da narrativa. A modernidade indaga sobre a representação e seu poder duplicador, que nos afasta das coisas. Representar é estabelecer formas de presença, articulando tempos e espaços na narrativa. Artaud retoma a morte de Dionysos como o lugar onde a origem se faz e desfaz, ponto indefinido no qual a cena do mundo se desteatraliza e se reteatraliza. O "teatro da 
crueldade" situa-se além e aquém da ação; o tempo é o presente sempre esgotado em si mesmo; o espaço desfaz diferenças palco/plateia. Ritual sem deuses, o teatro é pura potência de teatralidade, nos limites de desarticulação/rearticulação das relações atores/espectadores.

Desconstruídas as noções de encenador/encenação, já não se trata de partir de um texto e seu atrito com a cena. A performance situa-se no problema. Aqui nos reencontramos com Duchamp: a iconoclastia atinge a obra como objeto de contemplação, evidenciando a crise do suporte. Teatralidade, pictorialidade: circulação trágica voltada para o efêmero e o embate com a morte - da arte, inclusive, em eterno retorno. $O$ trágico pode ser compreendido como processo e potência de reengendramento. A esta tessitura, que qualificamos como "teatro contemporâneo", dirigimos nossas indagações, na fronteira carne/corpo: a crueldade lida com o cru. O naturalismo sonhou um teatro capaz de copiar o mundo a ponto de reduzir a zero a diferença entre um e outro; Artaud buscou este zero, recusando a representação para instaurar puras presenças. Mas o zero é um espelho do mundo (KUBRUSLY, 2012): vazio e pletora; os negativos são tão infinitos quanto os positivos. Ao se desfazerem, ação e cena fazem-se atravessar um pelo outro; público e atores mergulham em um presente espesso, feito de memórias da narrativa estilhaçada. As figuras transitam dentro e fora, enquanto os espectadores despojam-se desta qualificação para agir aquém e além do espelho. O "aqui" foi e é "lá", próximo e distante; o infinito contém-se no finito, contorcendo-se agora e sempre.

Assim os mares transmutam-se em Os sertões de Zé Celso. O zero move-se (orientase) num espaço não-orientável como a Banda de Möebius, um não-lugar que abriga o infinito no finito. Os eventos têm duração aion: passado e futuro comprimem o presente, zero que se transmuta em tudo. Os sujeitos eclodem em experiências múltiplas e entrecruzadas - permanente processo de tornar-se e deixar de ser no que os preenche e circunda. Os sertões são entrelugares contendo lugares, presença que se furta e eterno agora: tempo que se inicia ao finalizar-se. As memórias são afetos que fazem, dos agoras esvaídos, blocos de eternidade. Os agoras são ilusões: o espaço torna possível, ao não-ser, revelar-se como ser. A eternidade é não-tempo tanto quanto o presente, à diferença que este pode fingir-se de ex-istente (fora de si para deixar-se ver), na atuação de sujeitos eclodidos em de-cisões (divisões, fracionamentos) do indecidível (BADIOU, 1994). O agora (hac ora) é neste instante: demonstrativo preposicionado, advérbio a efetuar-se como verbo e gesto para inscrever-se na história e fazer de conta que há tempo. Os sertões são múltiplos; referem-se a possíveis, além e aquém de Euclides e Canudos; as evidências históricas cedem 
à experiência de mistérios e inesperados. São sugestões, metáforas, analogias trafegando pelo eterno e atualizando suas virtualidades em qualquer tempo e espaço, de précolombianos a pós-cabralinos. A "sertanicidade" expande-se e ultrapassa a História e a Geografia. O rizoma (DELEUZE \& GUATTARI, 1995) de Os sertões tanto pode ampliar ao infinito suas 26 horas de espetáculo como pode se dividir infinitamente: será sempre o reino do instante.

A desfronteirização da cena com seus espectadores tem um análogo nas condições políticas. Hoje, a soberania supranacional abala limites; descentraliza-se, desterritorializa-se e reterritorializa-se, expandindo-se incessantemente. Conjugam-se lazer, cultura e economia, arte e consumo, impondo-se o fim da jornada de trabalho como valor referencial. O Império (HARDT \& NEGRI, 2001) ambiciona suspender a história e tornar-se eterno. A globalização homogeneíza e heterogeneíza; com as multiplicidades, surgem horizontes inauditos de libertação. O Império abriga o Contra-Império, pois os contra-poderes podem espraiar-se tanto quanto os poderes, utilizando-se dos mesmos meios, na sociedade superinformada. Lidamos com a "multidão" (HARDT \& NEGRI, 2005) - reinvestimento na orgia e no êxtase criador - e não mais com o "povo", figurado pelo operário. O trabalho imaterial o retira da fábrica (relações de trabalho precarizadas) para submetê-lo a novas práticas de acumulação de valor, num modo de produção baseado na comunicação.

Potencializam-se revoltas e subjetivações: trágica desmedida da exploração capitalista, já antevista por Marx. A multidão, corpo coletivo ligado às redes imateriais de produção, comunicação e colaboração, conta com os afetos aí engendrados e salta para a História - presença no espaço e presente no tempo da cidade sublevada. É que os corpos ligados às redes se desmaterializam; mas, recompõem-se as virtualidades para atualizá-las na reinvenção humana e política das praças. O preço de não realizar isto seria limitar os usos tecnológicos a repetir o corpo na rede, numa metafísica onde a alma, perdida na modernidade, poderia recuperar-se.

A nova subjetividade afirma-se e compõe-se com as redes da informática, mas não se contém nelas porque os afetos escapam às equações e abraçam os enigmas. $\mathrm{O}$ novo corpo é velho: somos pré e pós-humanos, dotados de autocriação não apenas tecnológica, porque resistimos ao "corpo obsoleto" (STELARC, 1997) entregue às engenharias. O desafio é o limite de hibridização corpo/máquina: até que ponto a carne sustenta a identidade do humano e suporta o solapamento? 
Desde a invenção da imprensa, o corpo deixou de ser o mais completo artefato de comunicação. Teatro e literatura testemunham que vozes e coreografias da narrativa oral refugiaram-se nas entrelinhas. Ao fixar o texto sobre a página e abrir mão do ritual de contar (CHARTIER, 2002), passamos a "ler" o corpo, abstraindo-o e refazendo-o na imaginação. $\mathrm{O}$ ator moderno decifrava códigos textuais para lhes dar corpo. Hoje, ele não interpreta, porque já não dispõe de uma personagem com história pessoal e familiar transitando em tempo e espaço delimitados pela narrativa. As figuras, sem profundidade psíquica ou histórica, prendem-se a uma temporalidade desdobrada em conjugações de presente: potência de narratividade que guarda a memória do teatro e o transfigura numa topologia deslizante e afeita a dobras e contorções sobre si própria. Todos os jogos de espaço são possíveis, colocando-se em causa a noção de presença. Corpos dilaceram a carne para ligá-la a dispositivos tecnológicos. A marionete retorna, conectada eletronicamente: a carne não cessa de produzir figuras, diferenciando-se de si mesma e recompondo arquétipos.

$\mathrm{Na}$ sociedade de controle (DELEUZE, 1992), a quebra dos espelhos encena o êxodo permanente por um espaço que informa sobre corpos singulares em novas relações, conjugando estrutura e superestrutura, interagindo num campo simbólico do qual nada está fora. Solapam-se identidade e história. O êxodo das multidões é força subjetiva em sempre novos territórios igualmente sem fronteiras: demanda de cidadania global.

O cinema e os meios de comunicação mantêm, embora em fragmentos, algo dotado de inteireza narrativa (as séries e os folhetins) suficiente para constituir amparos referenciais dos quais se serve o teatro. Não são de surpreender as constantes retomadas dos clássicos em encenações que mantêm e reativam modelos de funcionamento da narrativa teatral.

No pós-fordismo, a comunicação atravessa a produção capitalista em todos os seus momentos e aspectos (serviços, finanças, indústria); a tecnologia está presente em todas as áreas da atividade humana, produzindo afetos, informação e cooperação. Emergem sujeitos na permanente indagação sobre a riqueza social; enfraquecida a delimitação das jornadas, como estabelecer a contradição trabalho/não-trabalho? Como estabelecer novas medidas de valor e referência? Neste campo de relações imanentes, caberá ao intelectual e ao artista posição não-vanguardista, acolhedora da (i)legibilidade do presente (VIRNO, 2008). Isso concerne à arte em sua feição trágica, não desligada do reino do comum. O presente é constelação onde diferentes temporalidades guardam semelhanças com o agora - analogia com o drama barroco visto por Benjamin (1984). 
O êxodo da multidão é radicalidade que recusa os monopólios das decisões políticas para melhor desmontar os poderes, num novo materialismo que afirma a sociabilidade e o conhecimento em rede. Essa indeterminação tem consistência trágica. A multidão abriga a multiplicidade - não se trata de pluralidade numérica, mas de potência da diferença; não é apanhada pela metonímia "povo", não tem à frente o proletariado. Ela é força disruptiva, no fim da "sociedade disciplinar" (FOUCAULT, 1995). Na "sociedade de controle" (DELEUZE, 1992), tecnologias de vigilância in(en)formam o sujeito.

A arte da presença é abalada: como conceber tragicidade que não incida sobre os corpos? Solapada a inteireza do corpo (falta de carne das imagens, hibridismos), como conceber o humano? É trágica a dor da carne performática? O teatro contemporâneo recupera o trágico na multiplicidade da memória que quer se ancorar no presente presença da carne dilacerada e feita de retalhos de lembranças (do corpo, da alma, da ação). Mais importante que contar histórias (embora elas sempre ressurjam), é por em ato sensações e virtualidades. No pós-humano retorna o corpo que se acreditava capaz de figurar totalidades, mas é um corpo sabedor de sua fusão com o inorgânico e o tecnológico, definitivamente incompleto sem as suas próteses e ligações em rede. A configuração é de um sujeito coletivo e espraiado, a colocar em causa a indivisibilidade que fundamenta a ideia de indivíduo.

É da opacidade do passado e da inapreensibilidade do presente somadas ao desfazimento da ação que surgem os não-heróis coletivos, como em $A$ negra Felicidade ${ }^{4}$. Os atores não representam personagens nomeados. Proferem seus discursos para fazer-nos tomar conhecimento de um processo de alforria em nome de Felicidade: os nomes correspondem a assinaturas de demandantes e demandados - eternas terceiras pessoas a se multiplicar em teias referenciais. Trata-se de um chamado à coletividade para a recuperação da memória da parresia, com propósitos de exortação: cobrança à História a desocultar-se e restabelecer a dívida com o presente; chamado ao presente a pronunciar-se e pagar também o que lhe cabe. A constelação de terceiras pessoas estrutura uma primeira pessoa coletiva: um nós metaforiza a multiplicidade em jogos de atravessamentos das singularidades. $\mathrm{O}$ exortador distingue-se a si mesmo neste papel e distingue o outro como exortado - todos reunidos na exaltação do "nós". Este discurso desconhece gêneros porque sua vocação é abraçar o trágico, o cômico, o satírico. A verdade será sempre incompleta, sempre recuada e afirmada, posta sob um véu de ironia para seu desmascaramento. Brecht não pode deixar de estar presente ao banquete de Dionísio.

\footnotetext{
${ }^{4}$ Direção de Moacir Chaves; Teatro Serrador, Rio, 2011.
} 
Em Os sertões como em $A$ negra Felicidade, trata-se de tocar o êxtase: o deslocamento do "si-mesmo" para "fora de si", num encontro com o outro. O trágico perfaz a ordem do contágio que se estende aos circunstantes, não mais apenas espectadores, mas partícipes do acontecimento da cena. Há violência no confronto dos discursos: inverdades, versões, pontos de vista. Assim se pode reinserir a verdade e a coragem para a sua busca. Nestes espetáculos, a falta de um herói individualizado distribui as vozes pela cidade: seus tempos e espaços, numa tragicidade não capturada pelo drama (ação).

Entre nós, as opiniões sobre futebol, TV ou atrocidades sustentam a sociabilidade. A comunicação "democrática" é alheia ao verdadeiro e ao falso (BADIOU, 1995). A verdade, por outro lado, exige fidelidade a um evento que perfura a lógica dos saberes e produz excesso de não-saber. Daí o advento do sujeito, um suporte para uma verdade (BADIOU, 1994). O sujeito é a localização de uma experiência múltipla e indeterminada; feixe de entrecruzamentos em um ponto. O processo é de permanente tornar-se sujeito. Por decidir o indecidível e apontar, p.ex., uma obra de arte, o sujeito compõe-se com ela, aderindo a uma nova "ética das verdades", sem deixar de ser ele mesmo - singularidade e espessura de multiplicidades, excesso de si sobre si. Sendo apenas alguém e, no entanto, derramado na condição de sujeito, é necessário continuar a pensar: manter os referentes histórico-políticos; abrigar, ao mesmo tempo, o não-sabido.

O corpo sem órgãos (DELEUZE, 1992) pulveriza o agir e dissolve a personagem: alguém que executa uma ação, deslocando-se em tempo e espaço. A multidão retorna ao coro de bacantes, o herói permanece em potência, tensionado entre passado e presente encontro de arkhé com techné. A loucura do Conselheiro (um "nós" canudense) faz refulgir a desrazão de todos os poderes.

A palavra "tragédia" foi apanhada pelos usos comunicacionais "versáteis" (BADIOU, 1995). Recuperá-la se faz por correlatos (trágico, tragicidade), entre a espectação e a embriaguez de Zé Celso. O performático impõe-se ao dramático, porque dram não é ação destinada à contemplação e ao entretenimento das massas, mas acontecimento (NIETZSCHE, 1999). O homem político é convocado via Internet, neste presente laminado e feito de informa(tiza)ções. Reencontramos a espessura da historicidade nas imprecações e apelos da praça e da cena contra a injustiça. O trágico é novamente sóbrio e ébrio.

\section{REFERÊNCIAS BIBLIOGRÁFICAS:}

APPIA, Adolph. A obra de arte viva. Lisboa, Editorial Arcádia, s.d.

ARTAUD, Antonin. O teatro e seu duplo. São Paulo, Max Limonad, 1984. 
BADIOU, Alain. Ética - um ensaio sobre a consciência do mal. Rio de Janeiro, Relume-Dumará, 1995. . Para uma nova teoria do sujeito. Rio de Janeiro, Relume-Dumará, 1994.

BENJAMIN, Walter. Origem do drama barroco alemão. São Paulo, Brasiliense, 1984.

BERGSON, Henri. Matéria e memória (ensaio sobre a relação do corpo com o espirito). São Paulo, Martins Fontes, 1990.

CHARTIER, Roger. Do palco à página. Rio de Janeiro, Casa da Palavra, 2002.

DELEUZE, Gilles. Conversacões. Rio de Janeiro, Ed. 34, 1992. . Mil platôs. vol. 1. Rio de Janeiro, Editora 34, 1995.

DERRIDA, Jacques. A escritura e a diferença. São Paulo, Perspectiva, 1995.

DIDEROT, Denis. Paradoxo sobre o comediante. São Paulo, Abril Cultural, 1973.

FOUCAULT, Michel. O governo de si e dos outros. São Paulo, WMF/ Martins Fontes, 2010. . Microfísica do poder. Rio de Janeiro, Graal, 1995.

HARDT, Michael \& NEGRI, Antonio. Império. Rio de Janeiro, Record, 2001. . Multidão. Rio de Janeiro, Record, 2005.

HERÁCLITO. Fragmentos (origem do pensamento). Edição bilíngue com tradução, introdução e notas de Emmanuel Carneiro Leão. Rio de Janeiro, Tempo Brasileiro, 1980.

HESÍODO. Teogonia. Tradução e Introdução de Jaa Torrano. São Paulo, Massao Ohno, 1981.

KLEIST, Heinrich Von. Teatro de marionetes. In: Cadernos de Cultura. Rio de Janeiro, MEC, s.d.

KUSBRUSLY, Ricardo Silva. O zero como espelho do mundo. Disponível em www.13snhct.sbhc.org.br/resources/anais/10/1343268221_ARQUIVO_RicardoSilvaKubrusly-O. 2012.

NIETZSCHE, Frederic. O caso Wagner: um problema para músicos / Nietz̧sche contra Wagner: dossiê de um psicólogo. São Paulo, Companhia das Letras, 1999.

Origem da tragédia. Lisboa, Guimarães Ed., 1982.

PLATÃO. Crátilo. Lisboa, Livraria Sá da Costa, 1963.

SCHILLER, Friedrich. Textos sobre o belo, o sublime e o trágico. Lisboa, Imprensa Nacional/Casa da Moeda, 1997.

STELARC. Das estratégias psicológicas às ciberestratégias: a protética, a robótica e a existência remota. In DOMINGUES, Diana. A arte no século XXI (a bumanização das tecnologias). São Paulo, UNESP, 1997.

VIRNO, Paolo. Virtuosismo e revolução. Rio de Janeiro, Civilização Brasileira, 2008.

\begin{abstract}
We brings to a decentered subjectivity, a fact that undermines the notions of the body itself, social and collective. The global capitalism undermines working, establishing new material and symbolic production. The study investigates the tragic power, in the overthrow of the theatrical action. It's imperative to examine the trajectories of body, time and space: support for the narration.
\end{abstract}

Keywords: tragic; contemporariness; tradition. 